\title{
Varenicline in the treatment of tobacco dependence
}

\author{
Karl Fagerström' \\ John Hughes ${ }^{2}$ \\ 'Smokers Information Centre, \\ Fagerström Consulting AB, Berga \\ Alle I, 25452 Helsingborg, Sweden; \\ ${ }^{2}$ University of Vermont, Burlington, \\ Vermont, USA
}

\begin{abstract}
Varenicline, a partial agonist of $\alpha_{4} \beta_{2}$ nicotinic acetylcholine receptors, is the most recently approved drug for smoking cessation. This paper reviews the outcomes of Phase 2 and Phase 3 clinical trials that assess the efficacy of varenicline in comparison to placebo and other smoking cessation pharmacotherapies, ie, sustained-release bupropion (bupropion SR) and nicotine transdermal patch. Varenicline has higher abstinence rates than placebo and the alternative active treatments at the end of standard regimen treatment periods. Significantly higher abstinence rates were also found with varenicline in comparison to both placebo and bupropion SR at the end of a 40-week non-treatment follow-up period. Varenicline typically tripled the abstinence rates compared with placebo. In addition, varenicline reduced craving and withdrawal symptoms as well as some of the positive experiences associated with smoking to a greater extent than placebo, bupropion SR, and nicotine replacement therapy (NRT). These findings are consistent with the proposed agonist/antagonist effects of varenicline. Preliminary studies assessing individual variables such as smoking dependency level and smoking reinforcement types provide justification to examine further the effects of varenicline according to these individual factors. Outcomes from such research could improve our understanding of varenicline's mechanism of action and could ultimately help clinicians to develop individualized smoking cessation programs. Also, given varenicline's ability to reduce the reward from smoking, it might be helpful to use it before cessation to motivate or prepare smokers for a quit attempt.
\end{abstract}

Keywords: varenicline, smoking cessation, nicotinic partial agonist

\section{Introduction}

Globally, cigarette consumption is still increasing, especially within developing countries (Mackay et al 2006). Even in the United States (US), where consumption has declined, approximately $21 \%$ of the adult population were still current smokers in 2006 (CDC 2007).

Stopping smoking not only halts, but can reverse the biological damage caused by smoking (CDC 2005). For example, stopping smoking has been shown to reduce the cardiovascular risk profile of former smokers (Terres et al 1994) and has been recognized as an important component of treatment for diseases such as respiratory disease (Tønnesen et al 2007) and lung cancer (Hecht 2002). After quitting, the smoking-related risk of heart disease mortality can be reduced by up to half (Critchley and Capewell 2003). Encouraging more smokers to quit would therefore significantly reduce the high morbidity and premature mortality rates currently associated with cigarette smoking (American Lung Association 2007).

However, stopping smoking does not come easily. While cigarette smoking is often thought of, and treated, as a lifestyle choice, nicotine is an addictive substance with similar potency to alcohol and opiates (US Department of Health and Human Services 1988). Nicotine dependence is a Substance Use Disorder in the Diagnostic 
and Statistical Manual of Mental Disorders, Fourth Edition - Revised (DSM-IV-TR) (APA 2000) and ranks higher on scales of physical and psychological dependency than alcohol, amphetamines, and cannabis (Nutt et al 2007). Repeated self-administration of nicotine from cigarettes is due to nicotine's effects on several neurotransmitters, including dopamine, released following nicotine's stimulation of central nicotinic acetylcholine receptors (nAChR) (Kelley 2002). In addition, withdrawal from nicotine results in a combination of psychological and physical symptoms leading to cravings and a continued desire to smoke (West et al 2006; Hughes 2007). These combined negative and positive reinforcing effects result in many smokers needing to make several quit attempts before successfully stopping smoking. The US Clinical Practice Guideline identifies nicotine addiction as a "chronic condition", and recommends smokers be given social and medicinal support by physicians and health care workers in order to help them quit (Fiore et al 2000).

\section{Background/history of treatments for smoking cessation}

The recommended behavioral treatment for smoking cessation is the type of cognitive behavioral therapy that emphasizes, among other things, motivation for stopping, smoking as a conditioned behavior, and alternative responses to craving and risk of relapse. Psychosocial treatments are recommended and provide additional efficacy, although they are not necessary for pharmacotherapy to be effective. However, clinical trials assessing the efficacy and safety of pharmacotherapies usually include brief counseling sessions in accordance with guidelines (Fiore et al 2000).

The first effective drug available as a smoking cessation aid was nicotine gum which received approval from the US Food and Drug Administration (FDA) in 1984. Thereafter several formulations followed. Nicotine itself is not carcinogenic. The biological damage resulting from cigarette smoking is due to other toxic and carcinogenic agents found in cigarette smoke (Hoffmann et al 2001). Consequently, nicotine replacement therapy (NRT) provides nicotine without the other damaging chemicals administered via cigarette smoke. The principle of using NRT as a smoking cessation aid is to wean smokers off tobacco dependence by substituting the nicotine, and therefore reducing the craving for cigarettes and withdrawal symptoms after quitting. Each NRT treatment has been shown to approximately double the odds of remaining abstinent from smoking in comparison to placebo (Silagy et al 2004).
The first non-nicotine drug to be introduced as a therapy for smoking cessation was sustained-release bupropion (bupropion SR) which was approved by the FDA for this use in 1997. Bupropion SR, a re-uptake inhibitor of dopamine and noradrenaline and a blocker of nicotine's activation of several neuronal nAChRs (Slemmer et al 2000) was originally developed as an atypical antidepressant, but its efficacy as a smoking cessation drug has been consistently shown in clinical trials. Bupropion SR also doubles the odds of successful cessation 12 months after quitting in comparison to placebo (Hughes et al 2004).

Fortunately, the growing interest in the need to give up smoking has been paralleled by an interest from the pharmaceutical industry to find and develop additional and more effective drugs as smoking cessation aids. Some of these have failed to be approved for this use by the FDA. For example, rimonabant, a cannabinoid receptor antagonist, was identified as a potential pharmacotherapy for smoking cessation, due to the implicated role of the endocannabinoid system in nicotine dependence (Fagerström and Balfour 2006; Sui and Tyndale 2007). Rimonabant reduced nicotine selfadministration in rats (Cohen et al 2002) and also decreased the ability of cues to elicit nicotine use in rats (Cohen et al 2005). However, a recent review of non-nicotinic therapies reported that rimonabant produced inconsistent results in 3 Phase 3 smoking cessation trials (Sui and Tyndale 2007). Rimonabant was not approved by the FDA for smoking cessation due to concerns about its psychiatric and neurologic adverse event (AE) profile (FDA 2007a).

Other pharmacotherapies have been specifically developed for smoking cessation. Nicotine vaccines have been formed to prevent nicotine from entering the brain, thereby blocking nicotine's effects (Fagerström and Balfour 2006; Sui and Tyndale 2007). While the safety of the current vaccines may not be a problem, early clinical trials cast some doubts over whether the vaccines will be effective enough to induce abstinence. Evidence from experiments with rats indicates that relapse prevention is probably a better indication for the vaccines unless good predictors of antibody response can be established before vaccination (Lindblom et al 2002). Another medication specifically developed for smoking cessation, varenicline, received FDA approval in 2006. In this paper we will review this latest addition in the physicians' armamentarium for helping smokers to quit.

\section{Development of varenicline}

Varenicline's synthesis was informed by basic research revealing the structure and functional properties of $\mathrm{nAChRs}$ 
and the effects of cytisine - a useful ligand for studying nAChRs (Pabreza et al 1991). Interestingly, cytisine has been historically used to help people stop smoking in Eastern Europe (Coe et al 2005; Etter 2006; Rollema et al 2007a).

The $\alpha_{4} \beta_{2}$ nAChR is believed to have the highest sensitivity to nicotine (Benowitz et al 1989; Fenster et al 1997). Activation of these receptors in the ventral tegmental area occurs when sufficient levels of nicotine are carried in the blood. The ventral tegmental area contains dopaminergic neurons which release dopamine via mesolimbic projections to the nucleus accumbens (Balfour 2004). Mice lacking either the $\alpha_{4}$ or $\beta_{2}$ subunits of the nAChR did not show the usual increased dopamine levels in the mesolimbic system in response to nicotine administration (Picciotto et al 1999; Marubio et al 2003). Consequently, these receptors are thought to play a mediating role in dopamine release following the intake of nicotine, which is in turn linked to nicotine's reinforcing effects (Kelley 2002; Pidoplichko et al 2004; Foulds 2006). Based on these observations, the $\alpha_{4} \beta_{2}$ receptor was identified as a potential target for a smoking cessation drug, especially with a partial agonist at this receptor subtype (Rollema et al 2007b). Varenicline was developed to have a high affinity for $\alpha_{4} \beta_{2} \mathrm{nAChR}$ in the mesolimbic dopamine system (Coe et al 2005; Rollema et al 2007a) and to act as a selective partial agonist of the $\alpha_{4} \beta_{2} \mathrm{nAChR}$. Like other partial agonists (eg, buprenorphine), varenicline has both agonist and antagonist effects. Binding at $\alpha_{4} \beta_{2} \mathrm{nAChR}$ is hypothesized to increase the dopaminergic tonus in relevant brain areas which decreases the craving for nicotine and alleviates the symptoms of withdrawal (agonist effects). In addition, blocking of nicotine's binding at these receptors is hypothesized to reduce nicotine-induced dopamine release and, consequently, its rewarding/reinforcing effects (antagonist effects) (Coe et al 2005; Rollema et al 2007a).

\section{Pharmacology of varenicline}

Evidence for varenicline's hypothesized agonist/antagonist dual mechanism of action has been demonstrated in both in vivo and in vitro studies. In terms of agonist effects, in brain slices taken from rats, varenicline stimulated $40 \%-60 \%$ less dopamine release than nicotine, consistent with the effects of a partial agonist (Rollema et al 2007a). In rats that were successfully trained to discriminate between nicotine and a saline solution using a 2-lever food pellet-reinforced drug discrimination procedure, varenicline fully substituted for the nicotine cue. In terms of antagonist effects, when varenicline was administered before nicotine, dopamine release was less than with nicotine alone (Rollema et al 2007a). Finally, in a nicotine self-administration model, varenicline was shown to reduce nicotine intake. Responses to nicotine following a maximally effective dose of varenicline were reduced to a similar level as responses to saline solution (Rollema et al 2007a). This could represent an antagonist effect, in which varenicline blocks the reinforcing effects of nicotine; or it could represent an agonist effect, in which varenicline serves as a substitute for nicotine (Rollema et al 2007a).

Varenicline has an elimination half-life of approximately 24 hours (Faessel et al 2006). The maximum absorption of varenicline occurs within about 3-4 hours following oral administration, and steady-state conditions are typically reached within 4 days following regular doses in healthy adults (Faessel et al 2006). Plasma concentrations and the pharmacokinetic parameters following the administration of varenicline were unaffected by the consumption of food and were similar for smokers and non-smokers (Faessel et al 2006). Varenicline has a simple metabolic and excretory profile in mice, rats, monkeys, and humans (Obach et al 2006). In humans, less than $10 \%$ of varenicline is excreted as metabolites and approximately $92 \%$ of varenicline is excreted unchanged in urine, indicating that the major route of clearance for varenicline is renal excretion (Obach et al 2006). Although their nAChR binding affinities have not been reported, it is highly unlikely that metabolites contribute to the activity of varenicline, since they either lose the amine function required for binding to $\mathrm{nAChRs}$, or are only present in urine (Obach et al 2006). If renal excretion is affected by kidney failure the dose can be decreased to $0.5 \mathrm{mg}$ twice daily (bid) which has also been found to be more effective than placebo in healthy subjects (Oncken et al 2006).

Partial agonists have been shown to be less susceptible to abuse in comparison to their full-agonist counterparts (Jasinski et al 1978; Jasinski and Preston 1985; Busto et al 1994). The subjective effects of varenicline significantly differed from those of a prototypic stimulant with abuse potential (ie, amphetamine) and were consistent with the profile of a drug with low abuse potential (McColl et al 2008). In addition, varenicline appears to be safe and well tolerated in healthy adults from 18 to 65 years of age (Gonzales et al 2006; Jorenby et al 2006; Nides et al 2006; Oncken et al 2006; Williams et al 2007), and also in healthy adults over 65 years (Burstein et al 2006). There are no contraindications with varenicline and no known drug interactions (Pfizer Ltd 2007).

\section{Varenicline in clinical use}

The efficacy and safety of varenicline for smoking cessation has been assessed in Phase 2 and Phase 3 randomized 
clinical trials. Results of 1 Phase 2 trial demonstrated that varenicline $1 \mathrm{mg}$ in either once daily or bid doses increased the odds of quitting in comparison to placebo during a 7-week treatment period ( 6 weeks active drug followed by 1 week placebo) (Table 1). However, the continuous abstinence rate of the participants given varenicline $1 \mathrm{mg}$ bid was greater than that of the $1 \mathrm{mg}$ once daily varenicline group (Table 1) (Nides et al 2006). Another Phase 2 trial used both titrated and non-titrated dosing and also showed that varenicline resulted in significantly more participants remaining continuously abstinent (Table 1) (Oncken et al 2006). In both studies, efficacy was maintained through 1-year follow-up (Table 1) (Nides et al 2006; Oncken et al 2006).

In these Phase 2 trials the most common AEs experienced by varenicline participants were nausea, insomnia, abnormal dreams, and headaches (Nides et al 2006; Oncken et al 2006). These trials established that the optimal dosing of varenicline, while maintaining an acceptable safety profile, was $1 \mathrm{mg}$ bid up titrated during the first week (Nides et al 2006; Oncken et al 2006) and that 12 weeks of drug treatment resulted in higher efficacy rates than the 7-week treatment period (Nides et al 2006; Oncken et al 2006) and thus, this dosing schedule was used in the 2 identically-designed Phase 3 trials $(0.5 \mathrm{mg}$ per day for the first 3 days, followed by $0.5 \mathrm{mg}$ bid for 4 days, then $1 \mathrm{mg}$ bid for the remainder of the 12 weeks).

In both these Phase 3 trials, participants were randomized to receive varenicline $1 \mathrm{mg}$ bid, bupropion SR $150 \mathrm{mg}$ bid, or placebo (1:1:1) (Gonzales et al 2006; Jorenby et al 2006).

Week 9-12 and Week 9-52 continuous abstinence rates were significantly greater for varenicline than placebo in both trials (Table 2) (Gonzales et al 2006; Jorenby et al
2006). Varenicline also achieved significantly greater efficacy over bupropion SR in Weeks 9-12 in both studies and this was maintained for Weeks 9-52 in 1 trial (Table 2) (Jorenby et al 2006). In the other trial, although the effect size was similar, this just missed statistical significance (Table 2) (Gonzales et al 2006).

Safety analyses of pooled data based on the 2 Phase 3 trials cited above (Gonzales et al 2006; Jorenby et al 2006) were conducted based on 2,045 subjects who received at least 1 dose of study medication (varenicline, $\mathrm{N}=692$; bupropion $\mathrm{SR}, \mathrm{N}=669$; or placebo, $\mathrm{N}=684$ ) (Nides et al 2008). Varenicline demonstrated an acceptable safety profile. Nausea (29\%), insomnia (14\%), and headache (14\%) were the most commonly reported AEs in the pooled varenicline data. A 29\% nausea figure seems high and was greater than nausea events reported in the bupropion SR participants (10\%) and placebo participants (9\%) (Nides et al 2008). However, discontinuation from study treatment due to nausea was rare and occurred in $3 \%$ of the varenicline participants, compared with $1 \%$ of the bupropion SR participants and less than 1\% of the placebo group. Nausea has consistently been the most frequently reported $\mathrm{AE}$ by participants taking varenicline, although the majority of these nausea experiences were reported as mild to moderate in intensity (Gonzales et al 2006; Jorenby et al 2006; Nides et al 2006; Oncken et al 2006; Nakamura et al 2007; Tsai et al 2007; Williams et al 2007). Furthermore, the onset and incidence of nausea peaked in the second week of treatment and reduced thereafter (Nides et al 2008). Overall, discontinuation from treatment for any reason occurred most frequently in the bupropion SR group (14\%), followed by varenicline (10\%), and then placebo (8\%) (Nides et al 2008).

Table I Abstinence rates of Phase 2 studies

\begin{tabular}{|c|c|c|c|c|c|c|c|c|}
\hline & \multicolumn{2}{|c|}{$\begin{array}{l}\text { CAR for any } 4 \text {-week } \\
\text { period during the } \\
\text { 7-week treatment phase }\end{array}$} & \multicolumn{2}{|c|}{$\begin{array}{l}\text { End of treatment CAR } \\
\text { Weeks } 9-12\end{array}$} & \multicolumn{2}{|c|}{ CAR Weeks 4-52 } & \multicolumn{2}{|c|}{ CAR Weeks 9-52 } \\
\hline $\begin{array}{l}\text { Nides et al } \\
2006(N=638)\end{array}$ & $\begin{array}{l}\text { Varenicline } \\
\text { I mg/day vs } \\
\text { placebo } \\
37 \% \text { vs I7\%; } \\
\text { OR } 2.97 \\
\text { P }<0.00 \text { I }\end{array}$ & $\begin{array}{l}\text { Varenicline } \\
\text { I mg bid vs } \\
\text { placebo } \\
48 \% \text { vs I7\%; } \\
\text { OR 4.7I; } \\
\text { P }<0.00 \text { I }\end{array}$ & $\begin{array}{l}\text { Varenicline } \\
0.5 \mathrm{mg} \text { bid vs } \\
\text { placebo }^{\mathrm{a}}\end{array}$ & $\begin{array}{l}\text { Varenicline } \\
\text { I mg bid vs } \\
\text { placebo }^{\mathrm{a}}\end{array}$ & $\begin{array}{l}\text { Varenicline } \\
\text { I mg/day vs } \\
\text { placebo } \\
6 \% \text { vs } 5 \% ; \\
\text { ns (p-value not } \\
\text { provided in } \\
\text { publication) }\end{array}$ & $\begin{array}{l}\text { Varenicline } \\
\text { I mg bid vs } \\
\text { placebo } \\
\text { I } 4 \% \text { vs } 5 \% \text {; } \\
\text { P }<0.0 \text { I }\end{array}$ & $\begin{array}{l}\text { Varenicline } \\
0.5 \mathrm{mg} \text { bid vs } \\
\text { placebo }^{\mathrm{a}}\end{array}$ & $\begin{array}{l}\text { Varenicline } \\
\text { I mg bid vs } \\
\text { placebo }^{\mathrm{a}}\end{array}$ \\
\hline $\begin{array}{l}\text { Oncken et al } \\
2006(N=647)\end{array}$ & & & $\begin{array}{l}44 \% \text { vs } 12 \% \\
\text { OR } 6.32 \\
P<0.001\end{array}$ & $\begin{array}{l}49 \% \text { vs } 12 \% \\
\text { OR } 8.07 \\
\text { P }<0.00 \text { I }\end{array}$ & & & $\begin{array}{l}\text { I } 9 \% \text { vs } 4 \% \\
\mathrm{P}<0.00 \text { I } \\
\text { (OR not } \\
\text { provided } \\
\text { in publication) }\end{array}$ & $\begin{array}{l}22 \% \text { vs } 4 \% ; \\
\mathrm{P}<0.00 \mathrm{I} \\
\text { (OR not } \\
\text { provided } \\
\text { in publication) }\end{array}$ \\
\hline
\end{tabular}

apooled titrated and non-titrated treatment groups.

Abbreviations: CAR, continuous abstinence rate; OR, odds ratio. 
Table 2 Abstinence rates of varenicline versus active comparator trials

\begin{tabular}{|c|c|c|c|c|c|c|c|c|}
\hline \multicolumn{5}{|c|}{ End of treatment CAR } & \multicolumn{4}{|c|}{ CAR through Week 52} \\
\hline & $\begin{array}{l}\text { Varenicline } \\
\text { I mg bid vs } \\
\text { NRT } \\
\text { transdermal } \\
\text { patch }^{\mathrm{a}}\end{array}$ & $\begin{array}{l}\text { Varenicline I } \\
\text { mg bid vs } \\
\text { placebo }^{\text {b }}\end{array}$ & $\begin{array}{l}\text { Bupropion SR } \\
150 \text { mg bid vs } \\
\text { placebo }^{\text {b }}\end{array}$ & $\begin{array}{l}\text { Varenicline I } \\
\text { mg bid vs } \\
\text { bupropion SR } \\
\text { I50 } \text { mg bid }^{\text {b }}\end{array}$ & $\begin{array}{l}\text { Varenicline I } \\
\text { mg bid vs } \\
\text { NRT } \\
\text { transdermal } \\
\text { patch }^{c}\end{array}$ & $\begin{array}{l}\text { Varenicline I } \\
\text { mg bid vs } \\
\text { placebo }^{\text {d }}\end{array}$ & $\begin{array}{l}\text { Bupropion } \\
\text { SR I50 mg } \\
\text { bid vs }^{\text {placebod }}\end{array}$ & $\begin{array}{l}\text { Varenicline } \\
\text { I mg bid vs } \\
\text { bupropion } \\
\text { SR I } 50 \mathrm{mg} \\
\text { bid }^{\text {d }}\end{array}$ \\
\hline $\begin{array}{l}\text { Gonzales } \\
\text { et al } 2006 \\
(\mathrm{~N}=1023)\end{array}$ & & $\begin{array}{l}44 \% \text { vs } 18 \% \\
\text { OR } 3.85 \\
\text { P }<0.00 \text { I }\end{array}$ & $\begin{array}{l}30 \% \text { vs } 18 \% \\
\text { OR, } 2.00 \\
P<0.001\end{array}$ & $\begin{array}{l}44 \% \text { vs } 30 \% \\
\text { OR I.93; } \\
\text { P < } 0.001\end{array}$ & & $\begin{array}{l}22 \% \text { vs } 8 \% \\
\text { OR } 3.09 \\
P<0.001\end{array}$ & $\begin{array}{l}16 \% \text { vs } 8 \% \\
\mathrm{P}=0.00 \mathrm{I} \\
\text { (OR not } \\
\text { provided in } \\
\text { publication) }\end{array}$ & $\begin{array}{l}22 \% \text { vs } \\
\text { I6\%; } \\
\text { OR I.46; } \\
P=0.057\end{array}$ \\
\hline $\begin{array}{l}\text { Jorenby } \\
\text { et al } 2006 \\
(N=1022)\end{array}$ & & $\begin{array}{l}44 \% \text { vs } 18 \% \\
\text { OR } 3.85 \\
P<0.001\end{array}$ & $\begin{array}{l}30 \% \text { vs } 18 \% \\
\text { OR } 2.02 \\
P=0.001\end{array}$ & $\begin{array}{l}44 \% \text { vs } 30 \% \\
\text { OR I.90; } \\
\text { P < } 0.001\end{array}$ & & $\begin{array}{l}23 \% \text { vs } 10 \% \\
\text { OR } 2.66 \\
P<0.001\end{array}$ & $\begin{array}{l}15 \% \text { vs } \\
10 \% ; \text { OR, } \\
1.50 ; \\
P=0.08\end{array}$ & $\begin{array}{l}23 \% \text { vs } \\
\text { I5\%; } \\
\text { OR I.77; } \\
P=0.004\end{array}$ \\
\hline $\begin{array}{l}\text { Aubin et al } \\
2008 \\
(N=746)\end{array}$ & $\begin{array}{l}56 \% \text { vs } \\
43 \% \\
\text { OR I.70; } \\
P<0.00 \text { I }\end{array}$ & & & & $\begin{array}{l}26 \% \text { vs } 20 \% \\
\text { OR I. } 40 ; \\
P=0.056\end{array}$ & & & \\
\hline
\end{tabular}

a'End of treatment CAR = varenicline Weeks 9-12; NRT Weeks 8-II.

'End of treatment CAR $=$ Weeks 9-12.

'Long-term CAR = varenicline Weeks 9-52; NRT Weeks 8-52.

'Long-term CAR = Weeks 9-52.

Abbreviations: CAR, continuous abstinence rate; NRT, nicotine replacement therapy; OR, odds ratio.

Varenicline has been compared with NRT in 2 studies. A non-randomized study compared varenicline with various NRTs in a smokers' clinic giving 7 group therapy sessions in addition to the medicine in smokers with and without prior or current mental illnesses. The cessation rate at 6 weeks (the only time point reported) was higher with varenicline than that with the use of 1 NRT, $72 \%$ vs. $61 \%$ (OR 1.7); however, varenicline did not result in a greater cessation rate than that established with the use of 2 NRTs. There were significantly more side effects with varenicline. The most common were nausea, disturbed sleep, vivid dreams, drowsiness, and constipation. Varenicline was similarly effective in those with mental illness and showed no evidence of worsening mental illnesses (Stapleton et al 2008).

The second study analyzed outcomes of randomized and treated participants in an open-label comparison of varenicline $1 \mathrm{mg}$ bid $(\mathrm{N}=376)$ with NRT, a $21 \mathrm{mg}$ transdermal patch, $(\mathrm{N}=370)$. Doses of NRT were $21 \mathrm{mg} /$ day for the first 6 weeks, $14 \mathrm{mg} /$ day for 2 weeks, and $7 \mathrm{mg} /$ day for 2 weeks. Continuous abstinence rate for the last 4 weeks of 12 weeks of varenicline standard regimen treatment was significantly greater than the continuous abstinence rate for the last 4 weeks of the standard regimen transdermal nicotine treatment, $56 \%$ and $43 \%$, respectively (OR 1.70; $<<0.001$ ) (Table 2) (Aubin et al 2008). The effect size was relatively similar at 52 weeks, but not statistically significant, $26 \%$ and $20 \%$, respectively (OR 1.40; $\mathrm{p}=0.056$ ) (Table 2 ) (Aubin et al 2008). In addition, varenicline showed a benefit over transdermal nicotine on craving, withdrawal symptoms, and feelings of smoking satisfaction reduction (Aubin et al 2008). Participants were aware of whether they had received NRT or varenicline and participants often believe that a new treatment or a prescription medication is superior to an older or over-the-counter medicine. How much of the superiority of varenicline was due to these expectancy effects is unknown.

Varenicline demonstrated an acceptable safety profile, although there were more reported AEs in the varenicline group than the NRT group. The most frequent AE in the varenicline group was nausea (varenicline, 37\%; NRT, $10 \%$ ), followed by insomnia (varenicline, $21 \%$; NRT, 19\%), and headache (varenicline, 19\%; NRT, 10\%) (Aubin et al 2008). There was also 1 report of suicidal ideation in the varenicline group (Aubin et al 2008). The FDA and the European Medicines Agency (EMEA) have recently warned providers and users of varenicline to monitor changes in behavior and increase awareness of cases of suicidal ideation and suicide attempts, due to some post-marketing reports of agitation, depressed mood, suicidal ideation and behavior in patients being treated with varenicline (EMEA 2007; FDA 2007b). As yet, there is no confirmed causal 
link between these symptoms and varenicline since stopping smoking by itself can in rare cases cause such symptoms (FDA 2007b).

The clinical trials discussed so far have included healthy adults from the Western world, the majority of whom were white. The efficacy of varenicline over placebo has also been demonstrated in Asian participants. A study conducted in Japan found that participants classified as nicotine dependent and randomized to varenicline $1 \mathrm{mg}$ bid achieved greater continuous abstinence rates for the last 4 weeks of a 12-week treatment phase than similar smokers randomized to receive placebo (Table 3) (Nakamura et al 2007). Superior efficacy of varenicline was maintained through Weeks 9-52, following a 40-week non-treatment followup period (Table 3) (Nakamura et al 2007). In Taiwan and Korea, participants in the varenicline group also obtained greater abstinence rates than placebo for Weeks 9-12 at the end of treatment (Table 3) (Tsai et al 2007) and through 12 weeks of post-treatment follow-up (Table 3) (Tsai et al 2007). No 52-week follow-up was conducted in this study. Both these Asian trials resulted in safety profiles similar to those reported in the Phase 3 studies conducted in the West (Gonzales et al 2006; Jorenby et al 2006; Nakamura et al 2007; Tsai et al 2007).

Further trials assessing varenicline as a smoking cessation aid are underway in participants with cardiovascular disease (www.clinicaltrials.gov identifier: NCT00282984) and chronic obstructive pulmonary disease (www.clinicaltrials.gov identifier: NCT00285012). Participants are being recruited to assess the effects of varenicline on mood in depressed outpatient smokers (www.clinicaltrials.gov identifier: NCT00525837), to assess the effects of varenicline as an adjunct to schizophrenia (www.clinicaltrials.gov identifier: NCT00492349), and to prompt quitting in ambivalent smokers (www.clinicaltrials. gov identifier: NCT00595868). A further trial is recruiting adolescents to assess the pharmacokinetic profile following multiple doses of varenicline in this population (www.clinicaltrials.gov identifier: NCT00463918).

\section{Degree of nicotine dependence and efficacy of varenicline}

Nicotine dependence, most often measured by the Fagerström Test for Nicotine Dependence (FTND), is a strong predictor of abstinence, particularly in non-treated smokers (eg, Fagerström and Schneider 1989; Hyland et al 2004; Foulds et al 2006). Analysis of pooled data from the two Phase 3 studies (Gonzales et al 2006; Jorenby et al 2006) examined abstinence according to baseline demographics of smoking status (Nides et al 2008). Subgroups were classified according to participant scores on the FTND (Heatherton et al 1991) (FTND scores of 0-3, 4-6, or 7-10); but also for number of cigarettes smoked per day (10 to $<20,20$ to $<30$, or $\geq 30$ ); and the time to the first cigarette of the day ( $\leq 30 \mathrm{~min}$ or $>30 \mathrm{~min}$ after waking). These last two are the most important questions in the FTND. In each of these subpopulations, lower-dependence smokers had higher abstinence rates, and participants randomized to receive varenicline achieved higher abstinence rates than those randomized to receive bupropion SR or placebo (Figure 1). To determine whether the efficacy of varenicline differed by degree of dependence, treatment by subgroup interactions were examined and these were not significant for daily cigarette consumption ( $p=0.16)$, FTND score $(p=0.26)$, and time to first cigarette of the day $(\mathrm{p}=0.40)$ (Nides et al 2008). These results indicate that varenicline is effective regardless of the degree of nicotine dependence although efficacy tends to decline as dependence increases.

Prior studies have found higher dependency is linked with lower success rates (Fiore et al 2000). One exception occurred in a nicotine nasal spray trial (Sutherland et al 1992). In this study, the heaviest smokers (assessed by plasma nicotine levels and dependence questionnaire responses at baseline) showed the greatest advantage of using the nicotine spray. While the likelihood of abstinence declined for the placebo group with increasing dependence, the rates of abstinence in the group given the active spray were similar, regardless of dependence level at baseline. With nicotine gum, the more

Table 3 Abstinence rates in other studies

\begin{tabular}{|c|c|c|c|}
\hline & CAR Weeks 9-I 2 & CAR Weeks 9-24 & CAR Weeks 9-52 \\
\hline & Varenicline I mg bid vs placebo & Varenicline I mg bid vs placebo & Varenicline I mg bid vs placebo \\
\hline Nakamura et al & $65 \%$ vs $40 \%$ & $38 \%$ vs $30 \%$ & $35 \%$ vs $23 \%$ \\
\hline $2007(N=515)$ & OR 2.98; $p<0.001$ & OR I.47; $\mathrm{p}=0.149$ & OR I.8I; $p=0.036$ \\
\hline Tsai et al 2007 & $60 \%$ vs $32 \%$ & $47 \%$ vs $22 \%$ & \\
\hline$(N=250)$ & OR 3.22; $\mathrm{p}<0.00 \mathrm{I}$ & OR 3.38; $p<0.001$ & \\
\hline
\end{tabular}

Abbreviations: CAR, continuous abstinence rate; $O R$, odds ratio. 


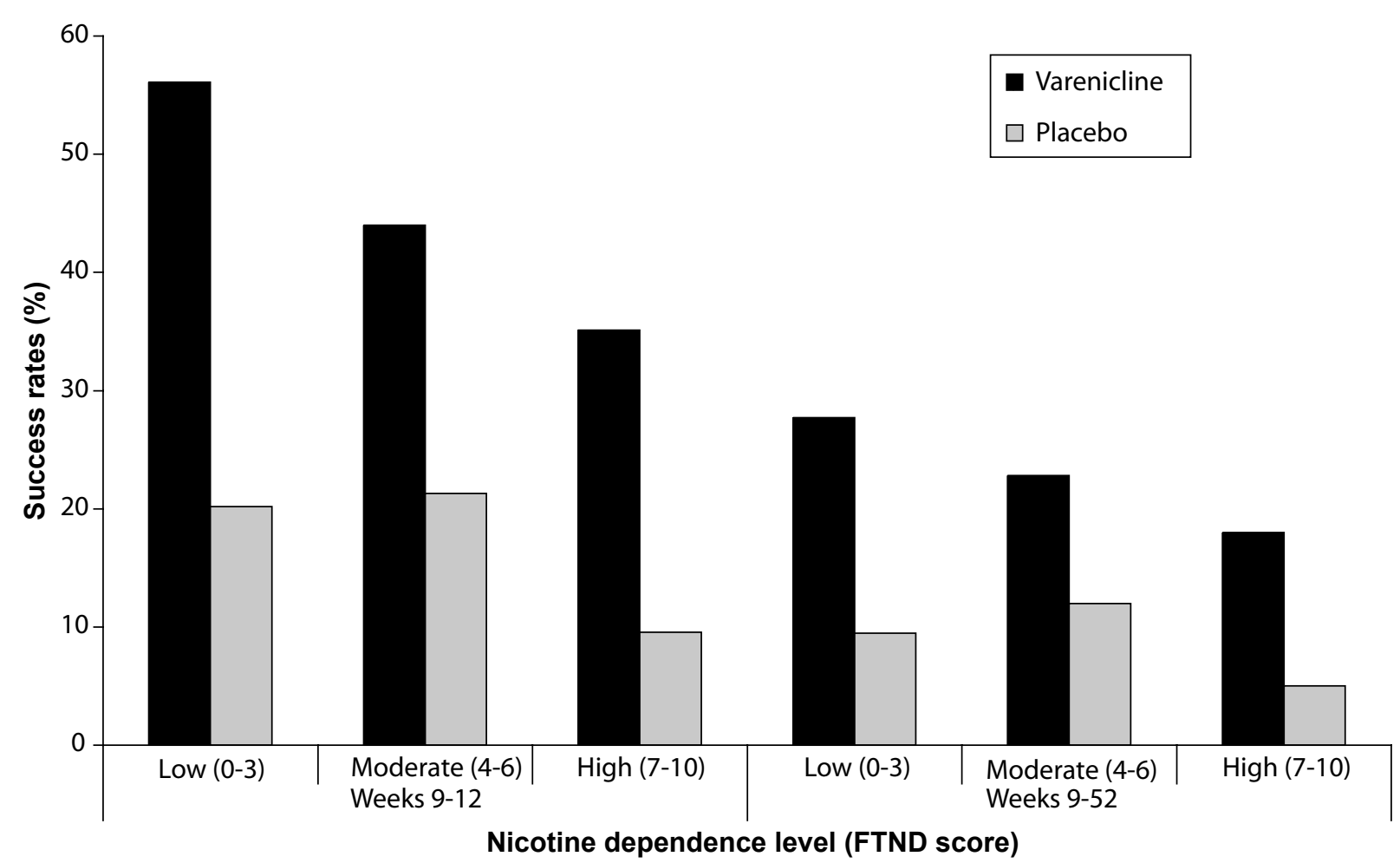

Figure I Percentage of varenicline and placebo participants achieving continuous abstinence at Weeks 9-12 and Weeks 9-52 according to nicotine dependence level (low/ $\mathrm{med} /$ high). Derived from data of Nides et al (2008).

Abbreviation: FTND, Fagerström Test for Nicotine Dependence.

dependent subjects do better with a $4 \mathrm{mg}$ strength than with a $2 \mathrm{mg}$ strength (Tønnesen et al 2007).

This finding raises the question of whether a higher dose, or longer treatment period, with varenicline would increase the success rate of the heaviest dependent smokers and give them the same chance to succeed as the lower dependent smokers. A maintenance trial has already established that an extended period of treatment with varenicline does help to maintain abstinence compared with placebo (Tonstad et al 2006). Participants who had successfully quit with varenicline at the end of a 12-week open-label treatment period were randomized to receive a further 12 weeks of treatment with varenicline or placebo. This advantage for varenicline continued through Weeks $13-52$ (44\% vs $37 \%$, respectively; OR 1.34; $\mathrm{p}=0.02)($ Tonstad et al 2006).

The maintenance trial also demonstrated an acceptable safety profile for participants during the extended treatment period with varenicline (Tonstad et al 2006). A long-term safety trial has further demonstrated that varenicline $1 \mathrm{mg}$ bid can be safely administered for up to 12 months (Williams et al 2007). Tolerability of varenicline was also shown to be acceptable following a single dose of $3 \mathrm{mg}$ in smoking participants, while there was a decreased tolerability at this dose in non-smokers (Faessel et al 2006). This finding of increased tolerability to higher doses according to smoking status might imply that smokers with a heavier nicotine intake may also be more tolerant of higher doses than smokers with a lower nicotine intake or at least a higher dose could be contemplated in patients without side effects. As yet, analyses directly testing the effect of extended or higher doses of varenicline treatment according to nicotine dependency level have not been conducted; however, the results would be interesting to observe.

\section{How to manage nausea with varenicline}

Incidents of nausea are less frequent with up-titrated, rather than non-titrated dosing (Oncken et al 2006) and symptoms of nausea may be reduced when varenicline is administered following food in comparison to fasted conditions (Faessel et al 2006). In clinical use, patients should be advised to take varenicline with food or at least water. However, if the recommended dose of varenicline is not tolerable, it may be necessary to reduce the dose (Pfizer Ltd 2007; Pfizer Inc 2008). The lower dose of varenicline $0.5 \mathrm{mg}$ bid has also been shown to be significantly more efficacious than placebo at the end 
of treatment and through 52 weeks of follow-up (Table 1) (Oncken et al 2006). Future strategies for reducing nausea with varenicline may include alternative formulations to avoid oral administration, such as via a transdermal route.

\section{Varenicline and positive or negative reinforcement for smokers}

Nicotine addiction can be reinforced by nicotine's ability to enhance vigilance, decrease anger and hunger, and improve cognitive function and mood (Benowitz 1996). However, drug reinforcement can also take the form of a reduction in negative effects from withdrawal such as restlessness, irritability, anxiety, tobacco craving, and insomnia, as well as reduced concentration levels (APA 2000).

These 2 types of reinforcement are crucial to understanding the complexity of nicotine addiction and how smoking behavior is maintained (Henningfield and Keenan 1993). Smokers might smoke predominantly for either positive reinforcement (to experience the positive effects during smoking) or negative reinforcement (to relinquish the negative symptoms of withdrawal between cigarettes). Other terms for describing roughly the same phenomenon are "trough maintainers" and "peak seekers" (Russell 1990). In addition, with increasing restrictions on smoking, continuing smokers may have moved from negative reinforcement to more positive reinforcement motives. The Michigan Nicotine Reinforcement Questionnaire was devised as a subjective measure of individual positive reinforcement and negative reinforcement for potential use as a diagnostic tool for individual intervention (Pomerleau et al 2003).

The first author of this review has also tried to capture the type of reinforcement (negative reinforcement: NR, or positive reinforcement: PR) in 1 single question:

"-If you have tried to stop smoking what was the most difficult, choose A or B.

A. The permanent state of something missing and that you did not function well (NR).

B. That you could not smoke at those special moments when it really taste well and makes you feel good (PR)."

This question was used to ascertain the reinforcement type of 73 participants from 2 European centers (Fagerström et al 2007) in the maintenance trial of varenicline described earlier in this review (Tonstad et al 2006). Point prevalence abstinence rates at 6 months were significantly higher for PR participants $(77 \%)$ than for NR participants $(52 \%$; $p<0.05)$ (Fagerström et al 2007). When abstinence data were analyzed in a $2 \times 2$ design (reinforcement type $\times$ high and low FTND score), the PR/low dependence group had a remarkably high abstinence rate of $85 \%$ in comparison to $68 \%$ of the $\mathrm{PR} /$ high dependence group. These data are shown in Figure 2, where they can be compared with the NR participants who showed lower success rates, with $58 \%$ in the low dependence group compared with $47 \%$ in the NR/high dependence group (Fagerström et al 2007) (Figure 2). These results indicate that varenicline may be more effective in helping smokers to quit when they have a low dependency on nicotine and are more influenced by the positive reinforcement of smoking than negative reinforcement factors. This interpretation of the data should be taken with caution due to the low number of participants included in these analyses; however, these results may provide justification for further research in this area.

The modified Cigarette Evaluation Questionnaire (mCEQ) evaluates subjective feelings of positive reward in participants who continue smoking and has been used to test the effects of varenicline on nicotine reinforcement. Varenicline participants in the Phase 3 trials also reported significantly lower scores of smoking satisfaction $(\mathrm{p}<0.001)$, psychological reward $(\mathrm{p}<0.001)$, enjoyment of respiratory tract sensations $(\mathrm{p}<0.05)$, and craving reduction $(\mathrm{p}<0.05)$ than the placebo group on subscales of the mCEQ during periods of continued smoking (Gonzales et al 2006; Jorenby et al 2006). Comparisons of these measures averaged over Weeks 1-7 of the varenicline versus NRT trial also established that varenicline significantly reduced each of these positive subjective feelings in comparison to nicotine patches $(\mathrm{p}<0.001)$ (Aubin et al 2008). The effect size of varenicline versus placebo was at least twice as high as bupropion SR versus placebo on mCEQ scales for smoking satisfaction, psychological reward, and enjoyment of respiratory tract sensations (Gonzales et al 2006). Together, these findings provide support for the proposed antagonist properties of varenicline (Coe et al 2005; Foulds 2006; Rollema et al 2007a).

\section{Varenicline and tobacco withdrawal symptoms}

Subjective measures of withdrawal experiences have been assessed with the Minnesota Nicotine Withdrawal Scale (MNWS) and The Brief Questionnaire of Smoking Urges (QSU-Brief) at baseline and at various other points during the trials (Gonzales et al 2006; Jorenby et al 2006). Consistent with the proposed agonist effects of varenicline (Coe et al 2005; Foulds 2006; Rollema et al 2007a), varenicline participants reported significantly lower urge to smoke ( $\mathrm{p}<0.001)$, negative affect $(\mathrm{p}<0.001)$, and restlessness $(\mathrm{p}<0.05)$ on the subscales of the MNWS and significantly lower craving scores on the QSU-Brief $(\mathrm{p}<0.001)$ in comparison to placebo in both the Phase 3 trials reported above (Gonzales 


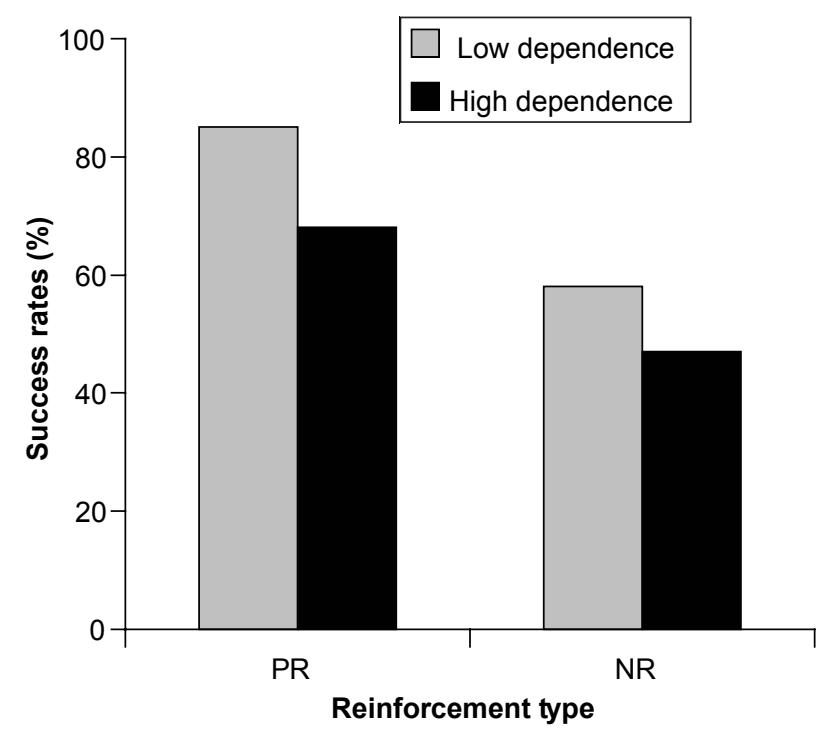

Figure 2 Percentage of varenicline participants who achieved point prevalence abstinence at 6 months according to nicotine dependence level (low vs high) and reinforcement type (positive, PR vs negative, NR). Derived from data of Fagerström et al (2007).

Abbreviations: PR, positive reinforcement; NR, negative reinforcement.

et al 2006; Jorenby et al 2006). The effect size of varenicline compared with placebo was also approximately double that of the effect size of bupropion SR compared with placebo for urge to smoke scores on the MNWS and craving scores on the QSU-Brief (Gonzales et al 2006).

\section{Can varenicline be used to increase motivation and self-efficacy?}

The relevance of the proposed antagonist effects of varenicline may be particularly pertinent to smokers with no interest in trying to quit, or who do not believe they are able to quit due to previously failed attempts. Reducing the rewarding effects of smoking may result in a reduced desire to continue smoking, or a desire to smoke less. Consequently, the dual mechanism of varenicline might mean that administering varenicline to such a group of ambivalent smokers could result in an increased motivation to cut down, or stop altogether due to its potential antagonist effects. Smokers with low, or no, motivation to stop smoking in the near future represent the majority of smokers (Wewers et al 2003). Therefore, if using varenicline can successfully motivate smokers to quit, the number of smokers who can benefit from varenicline may be substantially increased.

\section{Conclusions}

Varenicline is a partial agonist at the $\alpha_{4} \beta_{2} \mathrm{nAChR}$ and is the latest FDA-approved smoking cessation drug to be added to physicians' armamentarium. It has a straightforward pharmacokinetic profile with low abuse potential, and has no known contraindications with other drugs. Two large randomized, placebo-controlled trials have shown varenicline to be significantly more effective for smoking cessation in comparison to placebo and bupropion SR in the short- and long-term. Varenicline also resulted in significantly higher abstinence rates than NRT in the 1 open-label study of NRT.

Varenicline has demonstrated an acceptable safety profile for up to 1 year of treatment. Nausea is the most commonly experienced AE, but most experiences of nausea are of mild to moderate intensity and rarely cause drug discontinuation. The FDA and the EMEA have recently warned providers and users of varenicline to increase awareness of cases of suicidal ideation and suicide attempts, due to some post-marketing reports of changes of behavior in patients being treated with varenicline. As yet, there is no confirmed causal link between these symptoms and varenicline.

The proposed dual agonist/antagonist mechanism of action of varenicline has been supported by participants' subjective measures of experiences associated with smoking and smoking withdrawal. As one would expect with agonist properties, varenicline reduced craving and symptoms of withdrawal in comparison to placebo, bupropion SR, and NRT. Consistent with the proposed antagonist effects of the drug, varenicline also reduced some of the rewarding aspects of smoking in comparison to placebo, bupropion SR, and NRT.

These promising results warrant further investigation into the clinical use of varenicline for smoking cessation. Potential areas for further research might include assessing the effects of varenicline for different types of smokers and for different motivation levels.

Such research would help physicians to give individual advice regarding the most effective pharmacologic aids for smoking cessation according to the needs of the smoker.

\section{Acknowledgments}

Editorial support was provided by Brenda Smith PhD, of Envision Pharma and funded by Pfizer Inc. Dr Hughes was supported by a US National Institute of Drug Abuse Senior Scientist Award (DA-00490) and research grants (DA-11557 and 17825).

\section{Disclosures}

KF has consulted for numerous pharmaceutical companies with an interest in treatment of tobacco dependence. He is also a member of the Pfizer Varenicline Advisory Board. 
In $2007 \mathrm{JH}$ received research grants from the National Institute on Health and Pfizer Pharmaceuticals. In 2007-8 JH accepted honoraria or consulting fees from Abbot Pharmaceuticals; Acrux DDS; Aradigm; Cline, Davis and Mann; Constella Group; Consultants in Behavior Change; Evotec; Fagerstrom Consulting; Free and Clear; Insyght; Johns Hopkins University; Healthwise; National Institutes on Health; Pfizer Pharmaceuticals; Pinney Associates; Shire Health London; Temple University of Health Sciences; University of Arkansas; University of Auckland; University of Cantabria; University of Greifswald; University of Kentucky; and Xenova.

\section{References}

[APA] American Psychiatric Association. 2000. Diagnostic and Statistical Manual of Mental Disorders. 4th ed., revised. Washington DC: American Psychiatric Association.

American Lung Association. 2007. Trends in tobacco use [online]. Accessed 23 July 2007. URL:http://www.lungusa.org/site/apps/s/content. asp? $c=$ dvLUK9O0E $\& b=34706 \& c t=67648$.

Aubin H-J, Bobak A, Britton JR, et al. 2008. Varenicline versus transdermal nicotine patch for smoking cessation: results from a randomised, open-label trial. Thorax, 8 February 2008; [Epub ahead of print] doi:10.1136/thx.2007.090647.

Balfour DJK. 2004. The neurobiology of tobacco dependence: a preclinical perspective on the role of the dopamine projections to the nucleus accumbens. Nicotine Tob Res, 6:899-912.

Benowitz NL. 1996. Pharmacology of nicotine: addiction and therapeutics. Annu Rev Pharmacol Toxicol, 36:597-613.

Benowitz NL, Porchet H, Jacob P 3rd. 1989. Nicotine dependence and tolerance in man: pharmacokinetic and pharmacodynamic investigations. Prog Brain Res, 79:279-87.

Burstein AH, Fullerton T, Clark DJ, et al. 2006. Pharmacokinetics, safety, and tolerability after single and multiple oral doses of varenicline in elderly smokers. J Clin Pharmacol, 46:1234-40.

Busto U, Kaplan HL, Zawertailo L, et al. 1994. Pharmacologic effects and abuse liability of bretazenil, diazepam, and alprazolam in humans. Clin Pharmacol Ther, 55:451-63.

Centers for Disease Control and Prevention. 2005. Annual smokingattributable mortality, years of potential life lost, and productivity losses - United States, 1997-2001. MMWR Morb Mortal Wkly Rep, 54:625-8.

Centers for Disease Control and Prevention. 2007. Cigarette smoking among adults - United States, 2007. MMWR Morb Mortal Wkly Rep, 56:1157-61.

Coe JW, Brooks PR, Vetelino MG, et al. 2005. Varenicline: an $\alpha_{4} \beta_{2}$ nicotinic receptor partial agonist for smoking cessation. J Med Chem, 48:3474-7.

Cohen C, Perrault G, Voltz C, et al. 2002. SR141716, a central cannabinoid $(\mathrm{CB}(1))$ receptor antagonist, blocks the motivational and dopamine-releasing effects of nicotine in rats. Behav Pharmacol, 13:451-63.

Cohen C, Perrault G, Griebel G, et al. 2005. Nicotine-associated cues maintain nicotine-seeking behavior in rats several weeks after nicotine withdrawal: Reversal by the cannabinoid (cb1) receptor antagonist, rimonabant (sr141716). Neuropsychopharmacology, 30:145-55.

Critchley JA, Capewell S. 2003. Mortality risk reduction associated with smoking cessation in patients with coronary heart disease: a systematic review. JAMA, 290:86-97.

[EMEA] European Medicines Agency. 2007. Press Release. European Medicines Agency concludes new advice to doctors and patients for Champix needed [online]. Accessed 12 March 2008. URL: http://www. emea.europa.eu/pdfs/general/direct/pr/59551607en.pdf.
Etter J-F. 2006. Cytisine for smoking cessation: a literature review and meta-analysis. Arch Intern Med, 166:1553-9.

Faessel HM, Smith BJ, Gibbs MA, et al. 2006. Single-dose pharmacokinetics of varenicline, a selective nicotinic receptor partial agonist, in healthy smokers and nonsmokers. J Clin Pharmacol, 46:991-8.

Fagerström KO, Schneider NG. 1989. Measuring nicotine dependence in tobacco smoking: a review of the Fagerström Tolerance Questionnaire. J Behav Med, 12:159-82.

Fagerström KO, Balfour DJK. 2006. Neuropharmacology and potential efficacy of new treatments for tobacco dependence. Expert Opin Investig Drugs, 15:107-16.

Fagerström KO, Jimenez-Ruiz CA, Astray Mochales J, et al. 2007. Can smoking for positive or negative reinforcement together with dependence help us better diagnose smokers? J Smoking Cessation, 2:5-7.

[FDA] Food and Drug Administration. 2007a. NDA 21-888. Zimulti (rimonabant) Tablets, $20 \mathrm{mg}$. Sanofi Aventis. Advisory Committee - June 13, 2007 [online]. Accessed 2 Oct 2007. URL: http://www.fda.gov/ohrms/ dockets/ac/07/briefing/2007-4306b1-fda-backgrounder.pdf.

[FDA] Food and Drug Administration. 2007b. Early communication about an ongoing safety review: Varenicline (marketed as Chantix) [online]. Accessed 14 Jan 2008. URL: http://www.fda.gov/cder/drug/ early_comm/varenicline.htm.

Fenster CP, Rains MF, Noerager B, et al. 1997. Influence of subunit composition on desensitization of neuronal acetylcholine receptors at low concentrations of nicotine. J Neurosci, 17:5747-59.

Fiore MC, Bailey WC, Cohen SJ, et al. 2000. Treating tobacco use and dependence. Clinical Practice Guideline [online]. Accessed 13 Feb 2007. URL: http://www.surgeongeneral.gov/tobacco/ treating_tobacco_use.pdf.

Foulds J. 2006. The neurobiological basis for partial agonist treatment of nicotine dependence: varenicline. Int J Clin Pract, 60:571-6.

Foulds J, Gandhi KK, Steinberg MB. 2006. Factors associated with quitting smoking at a tobacco dependence treatment clinic. Am J Health Behav, 30:400-12.

Gonzales D, Rennard SI, Nides M, et al. 2006. Varenicline, an $\alpha_{4} \beta_{2}$ nicotinic acetylcholine receptor partial agonist, vs sustained-release bupropion and placebo for smoking cessation: a randomized controlled trial. JAMA, 296:47-55.

Heatherton TF, Kozlowski LT, Frecker RC, et al. 1991. The Fagerström Test for Nicotine Dependence: a revision of the Fagerström Tolerance Questionnaire. Br J Addict, 86:1119-27.

Hecht SS. 2002. Cigarette smoking and lung cancer: chemical mechanisms and approaches to prevention. Lancet Oncol, 3:461-9.

Henningfield JE, Keenan RM. 1993. Nicotine delivery kinetics and abuse liability. J Consult Clin Psychol, 61:743-50.

Hoffmann D, Hoffmann I, El-Bayoumy K. 2001. The less harmful cigarette: a controversial issue. A tribute to Ernst L. Wynder. Chem Res Toxicol, 14:767-90.

Hughes J, Stead L, Lancaster T. 2004. Antidepressants for smoking cessation. Cochrane Database Syst Rev, CD000031.

Hughes JR. 2007. Effects of abstinence from tobacco: valid symptoms and time course. Nicotine Tob Res, 9:315-27.

Hyland A, Li Q, Bauer JE. 2004. Predictors of cessation in a cohort of current and former smokers followed over 13 years. Nicotine Tob Res, 6(Suppl 3):S363-9.

Jasinski DR, Pevnick JS, Griffith JD. 1978. Human pharmacology and abuse potential of the analgesic buprenorphine: a potential agent for treating narcotic addiction. Arch Gen Psychiatry, 35:501-16.

Jasinski DR, Preston KL. 1985. Assessment of dezocine for morphine-like subjective effects and miosis. Clin Pharmacol Ther, 38:544-8.

Jorenby DE, Hays JT, Rigotti NA, et al. 2006. Efficacy of varenicline, an $\alpha_{4} \beta_{2}$ nicotinic acetylcholine receptor partial agonist, vs placebo or sustained-release bupropion for smoking cessation: a randomized controlled trial. JAMA, 296:56-63.

Kelley AE. 2002. Nicotinic receptors: addiction's smoking gun? Nat Med, 8:447-9. 
Lindblom N, de Villiers SHL, Kalayanov G, et al. 2002. Active immunization against nicotine prevents reinstatement of nicotine-seeking behavior in rats. Respiration, 69:254-60.

Mackay J, Eriksen M, Shafey O. 2006. The Tobacco Atlas. 2nd ed. Atlanta, Georgia, USA: American Cancer Society.

Marubio LM, Gardier AM, Durier S, et al. 2003. Effects of nicotine in the dopaminergic system of mice lacking the alpha4 subunit of neuronal nicotinic acetylcholine receptors. Eur J Neurosci, 17:1329-37.

McColl S, Burstein A, Reeves K, et al. 2008. Human abuse liability of the smoking cessation drug varenicline in smokers and nonsmokers. Clin Pharmacol Ther, February 20 2008; [Epub ahead of print] doi:10.1038/ sj.clpt.6100510.

Nakamura M, Oshima A, Fujimoto Y, et al. 2007. Efficacy and safety of varenicline, an $\alpha_{4} \beta_{2}$ nicotinic acetylcholine receptor partial agonist, in a 12-week, randomized, placebo-controlled, dose-response study with 40-week follow-up for smoking cessation in Japanese smokers. Clin Ther, 29:1040-56.

Nides M, Glover E, Reus V, et al. 2008. Varenicline versus bupropion for smoking cessation: A pooled analysis. Am J Health Behav, 32: 664-75.

Nides M, Oncken C, Gonzales D, et al. 2006. Smoking cessation with varenicline, a selective $\alpha_{4} \beta_{2}$ nicotinic receptor partial agonist: results from a 7-week, randomized, placebo- and bupropion-controlled trial with 1-year follow-up. Arch Intern Med, 166:1561-8.

Nutt D, King LA, Saulsbury W, et al. 2007. Development of a rational scale to assess the harm of drugs of potential misuse. Lancet, 369:1047-53.

Obach RS, Reed-Hagen AE, Krueger SS, et al. 2006. Metabolism and disposition of varenicline, a selective $\alpha_{4} \beta_{2}$ acetylcholine receptor partial agonist, in vivo and in vitro. Drug Metab Dispos, 34:121-30.

Oncken C, Gonzales D, Nides M, et al. 2006. Efficacy and safety of the novel selective nicotinic acetylcholine receptor partial agonist, varenicline, for smoking cessation. Arch Intern Med, 166:1571-7.

Pabreza LA, Dhawan S, Kellar KJ. 1991. [3h]cytisine binding to nicotinic cholinergic receptors in the brain. Mol Pharmacol, 39:9-12.

Pfizer Inc. 2008. Chantix ${ }^{\mathrm{TM}}$ (varenicline) tablets prescribing information drug insert. New York, NY, USA: Pfizer Inc.

Pfizer Ltd. 2007. Champix ${ }^{\mathrm{TM}}$ summary of product characteristics. UK.

Picciotto MR, Zoli M, Changeux JP. 1999. Use of knock-out mice to determine the molecular basis for the actions of nicotine. Nicotine Tob Res, 1(Suppl 2):S121-5; discussion S139-40.

Pidoplichko VI, Noguchi J, Areola OO, et al. 2004. Nicotinic cholinergic synaptic mechanisms in the ventral tegmental area contribute to nicotine addiction. Learn Mem, 11:60-9.

Pomerleau OF, Fagerström K, Marks JL, et al. 2003. Development and validation of a self-rating scale for positive- and negative-reinforcement smoking: the Michigan Nicotine Reinforcement Questionnaire. Nicotine Tob Res, 5:711-8.
Rollema H, Chambers LK, Coe JW, et al. 2007a. Pharmacological profile of the $\alpha_{4} \beta_{2}$ nicotinic acetylcholine receptor partial agonist varenicline, an effective smoking cessation aid. Neuropharmacology, 52:985-94.

Rollema H, Coe JW, Chambers LK, et al. 2007b. Rationale, pharmacology and clinical efficacy of partial agonists of $\alpha_{4} \beta_{2}$ nAHc receptors for smoking cessation. Trends Pharmacol Sci, 28:316-25.

Russell MAH. 1990. Nicotine intake and its control over smoking. In Wonnacott S, Russell MAH, Stoleman IP (eds.) Nicotine psychopharmacology. Oxford, U.K.: Oxford University Press. pp. 374-418.

Silagy C, Lancaster T, Stead L, et al. 2004. Nicotine replacement therapy for smoking cessation. Cochrane Database Syst Rev, CD000146.

Slemmer JE, Martin BR, Damaj MI. 2000. Bupropion is a nicotinic antagonist. J Pharmacol Exp Ther, 295:321-27.

Stapleton JA, Watson L, Spirling LI, et al. 2008. Varenicline in the routine treatment of tobacco dependence: a pre - post comparison with nicotine replacement therapy and an evaluation in those with mental illness. Addiction, 103:146-54.

Sui ECK, Tyndale RF. 2007. Non-nicotinic therapies for smoking cessation. Ann Rev Pharmacol Toxicol, 47:541-64.

Sutherland G, Stapleton JA, Russell MAH, et al. 1992. Randomised controlled trial of nasal nicotine spray in smoking cessation. Lancet, 340:324-29.

Terres W, Becker P, Rosenberg A. 1994. Changes in cardiovascular risk profile during the cessation of smoking. Am J Med, 97:242-9.

Tønnesen P, Carrozzi L, Fagerström K, et al. 2007. Smoking cessation in patients with respiratory diseases: a high priority, integral component of therapy. Eur Respir J, 29:390-417.

Tonstad S, Tønnesen P, Hajek P, et al. 2006. Effect of maintenance therapy with varenicline on smoking cessation: a randomized controlled trial JAMA, 296:64-71.

Tsai S-T, Cho H-J, Cheng H-S, et al. 2007. A randomized, placebocontrolled trial of varenicline, a selective $\alpha_{4} \beta_{2}$ nicotinic acetylcholine receptor partial agonist, as a new therapy for smoking cessation in Asian smokers. Clin Ther, 29:1027-39.

US Department of Health and Human Services. 1988. The Health Consequences of Smoking. Nicotine Addiction. A Report of the Surgeon General. Rockville, Maryland.

West R, Ussher M, Evans M, et al. 2006. Assessing DSM-IV nicotine withdrawal symptoms:a comparison and evaluation of five different scales. Psychopharmacology (Berl). 184:619-27.

Wewers ME, Stillman FA, Hartman MS, et al. 2003. Distribution of daily smokers by stage of change: Current Population Survey results. Prev Med, 36:710-20.

Williams KE, Reeves K, Billing CB Jr, et al. 2007. A double-blind study evaluating the long-term safety of varenicline for smoking cessation. Curr Med Res Opin, 23:793-801. 
